\title{
A behavioral cascade of HIV seroadaptation among US men who have sex with men in the era of $\operatorname{PrEP}$ and $\mathrm{U}=\mathrm{U}$
}

Steven M. Goodreau ${ }^{1}$

Kevin M. Maloney ${ }^{2}$

Travis H. Sanchez ${ }^{2}$

Martina Morris ${ }^{3}$

Patrick Janulis ${ }^{4}$

Samuel M. Jenness ${ }^{2}$

1. Dept. of Anthropology, University of Washington, Seattle WA. 2. Department of

Epidemiology, Rollins School of Public Health, Emory University, Atlanta, GA. 3. Departments of Statistics and Sociology, University of Washington, Seattle WA. 4. Department of Medical Social Sciences, Northwestern University Feinberg School of Medicine, Chicago, IL.

Suggested running head: HIV seroadaptation among US men who have sex with men in the era of PrEP and $\mathrm{U}=\mathrm{U}$

\section{Corresponding author:}

Steven M. Goodreau

Campus Box 353100

University of Washington

Seattle, WA 91895 USA

Phone: +1 (206) 685-3870

Fax: +1 (206) 543-3285

Email: goodreau@uw.edu 


\begin{abstract}
Seroadaptive behaviors help to reduce HIV risk for some men who have sex with men (MSM), and have been well documented in a range of MSM populations. Advancements in biomedical prevention have changed the contexts in which seroadaptive behaviors occur. We thus sought to estimate and compare the prevalence of four stages of the "seroadaptive cascade" in the recent era: knowledge of own serostatus, knowledge of partner serostatus; serosorting (matching by status), and condomless anal intercourse. Serosorting overall appeared to remain common, especially with casual and one-time partners. Although PrEP use did not impact status discussion, it did impact serosorting and the likelihood of having condomless anal intercourse. For respondents not diagnosed with HIV and not on PrEP, condomless anal intercourse occurred in just over half of relationships with partners who were not on treatment. Biomedical prevention has intertwined with rather than supplanted seroadaptive behaviors, while contexts involving neither persist.
\end{abstract}

Key words: HIV-1; men who have sex with men; seroadaptive behaviors; pre-exposure prophylaxis (PrEP); condom use; treatment as prevention (TasP) 


\section{INTRODUCTION}

Seroadaptive behaviors represent a longstanding HIV risk reduction strategy practiced by men who have sex with men (MSM) [1-25]. While selection of sexual partners by serostatus

("serosorting") is most commonly discussed, seroadaptive behaviors include multiple other types of serostatus-based decisions, e.g. selection of sexual acts (e.g. oral vs. anal), selection of sexual role ("seropositioning", i.e. insertive vs receptive), and decisions around condom use. Akin to HIV care, these can be framed as a "seroadaptive cascade" (Figure 1). While seroadaptive behaviors alone are clearly an imperfect strategy for preventing HIV acquisition [26-28], some MSM are more successful in adhering to them than to condom use [29], the latter of which has long been on the decline among MSM overall [15,30]. Two meta-analyses [31,32] found that men practicing serosorting have lower HIV incidence than those who practice condomless anal intercourse (CLAI) without regard to partner status. This confirms that serosorting, and perhaps other seroadaptive behaviors, play an important role towards HIV harm reduction among MSM.

Recent developments in biomedical HIV prevention have fundamentally changed the prevention landscape, and thus the contexts shaping the adoption of seroadaptive behaviors. Both preexposure prophylaxis (PrEP) and treatment as prevention (TasP, known commonly as "undetectable = untransmittable", or "U=U") work to prevent the spread of HIV through the actions of a single individual. That is, a man taking PrEP as recommended might presume that he has high, consistent protection from HIV acquisition, regardless of his partner's status. A similar situation holds for a man with HIV who is adherent to ART and has exhibited durable HIV viral load suppression, with respect to transmission. This may lead to men in either group 
medRxiv preprint doi: https://doi.org/10.1101/2020.11.25.20238758; this version posted November 29, 2020. The copyright holder for this

It is made available under a CC-BY-NC-ND 4.0 International license .

deciding that they need not engage in explicit discussion of HIV status, nor adapt behavior based on perceived status concordance or discordance. We might thus imagine that these biomedical tools have influenced seroadaptive behaviors for these men, and possibly even for men who are HIV-negative and not on PrEP as well through broader changes in safer-sex norms.

Seroadaptation appears to have declined overall as PrEP has expanded in San Francisco [33], and subsequent analyses that compared men on PrEP to those off have found some evidence for lower levels of seroadaptive behaviors among the former [34,35].

In practice, not all men on PrEP or ART maintain perfect adherence [36-38] or full selfawareness of their adherence level $[39,40]$, and cases of acquisition by those adherent to PrEP, although rare, do exist [41]. Since individuals may vary in their conceptualizations of risk and the confidence they place in any individual strategy, some proportion may continue to engage in seroadaptive behaviors in conjunction with biomedical strategies. These types of decisions likely play out differently by type of relationships (e.g. main, casual, or one-time) [23], given differences in level of trust around accurate disclosure $[42,43]$, or in trade-offs between prevention and intimacy $[44,45]$. Given all of the considerations, detailed assessments of current seroadaptive behaviors for MSM across serostatuses or biomedical prevention engagement in multiple settings can provide insight about the current contexts for continued potential HIV transmissions.

Measuring seroadaptive behaviors is complicated by multiple factors. For one, observed behavioral patterns may emerge from other causes besides explicit intentionality $[3,19,29,46]$. For instance, a preponderance of seroconcordant partners could stem from assortative mixing not 
on serostatus but on attributes that correlate with it, such as age and race/ethnicity; however, some of the effects on epidemiology may be similar regardless of the actual drivers of partner selection. Another issue is endogenous transmission-i.e. that partners match in HIV status not because of selection but because initially serodiscordant relationships transition to seroconcordant-positive via transmission within the relationship. Finally, knowledge of both self and partner serostatus is generally imperfect and time-varying (until someone is diagnosed with HIV and discloses this). Nevertheless, when considering how knowledge of status impacts behavior, that knowledge itself is a relevant measure, regardless of whether it matches true serostatus.

In this paper, we measure the state of seroadaptive behaviors among MSM during the era of PrEP and $\mathrm{U}=\mathrm{U}$. We interrogate four steps in the seroadaptive cascade: HIV testing, disclosure, partner selection, and sexual act/condom use selection. When appropriate, we disaggregate HIVnegative respondents by PrEP status. Our primary hypothesis is that men on PrEP will exhibit less seroadaptation than men who are HIV-negative but not on PrEP. We predict that men who report not knowing their own HIV status will exhibit the lowest levels of seroadaptation. Predicting the relative levels of seroadaptivity between men on PrEP and those with HIV is less straightforward. Regardless, we hypothesize that for all groups, both knowledge of and concordance in serostatus will be highest in more long-term relationships. By considering each stage and the relational types in which they occur, we aim for our work to provide the evidence needed to parametrize further quantitative analyses, such as mathematical modeling or the development of individual or relational risk scores, that can help to assess and thus intervene 
medRxiv preprint doi: https://doi.org/10.1101/2020.11.25.20238758; this version posted November 29, 2020. The copyright holder for this preprint (which was not certified by peer review) is the author/funder, who has granted medRxiv a license to display the preprint in perpetuity.

It is made available under a CC-BY-NC-ND 4.0 International license .

upon the contexts in which probable transmission events continue to occur in the biomedical prevention era.

\section{METHODS}

We used data from the ARTnet study, a web-based sexual network survey of MSM conducted in conjunction with the long-standing American Men's Internet Survey (AMIS) in two waves (Jul. 2017-Feb. 2018 and Sep. 2018-Jan. 2019). Detailed methods are published for both ARTnet [47] and AMIS [48-51]. Recruitment for AMIS occurred through banner ads on websites and social network applications popular with MSM. Respondents who completed AMIS were requested to participate in ARTnet, which included additional questions on sexual networks and behaviors with male partners. Eligibility criteria for ARTnet included being aged 15-65, assigned male sex at birth, having cisgender male identity, and having any lifetime sexual activity with another man.

Most of our outcomes of interest used relationships as the unit of analysis. Respondents were asked summary questions about their relationship history and detailed questions about their most recent male partners (up to 5) within the last year. Relationships were categorized into three types: main ("someone that you feel committed to above all others, someone you might call your boyfriend, significant other, life partner or husband"), casual (anyone else a respondent has had sex with more than once); and one-time. 
medRxiv preprint doi: https://doi.org/10.1101/2020.11.25.20238758; this version posted November 29, 2020. The copyright holder for this preprint (which was not certified by peer review) is the author/funder, who has granted medRxiv a license to display the preprint in perpetuity.

It is made available under a CC-BY-NC-ND 4.0 International license .

Respondents were categorized by self-reported knowledge of HIV status: HIV-positive (those who had ever had a positive HIV test); HIV-negative (those who had tested but never with a positive result); and HIV-unknown (those who had never tested, never received their results, or reported not knowing their results). Partners were similarly categorized by the respondent's reported knowledge of their serostatus; here, HIV-unknown included cases where respondent said their partner had never been tested, their partner did not know his status, or that they did not know their partner's status.

Respondent's PrEP use was categorized on a per-partnership basis, i.e. whether they were taking PrEP during none, some, or all of the relationship. For behaviors by PrEP use, we compared cases with PrEP use during all or none of the relationship, since with partial PrEP use we cannot tell which behaviors occurred during the period with and without PrEP. To determine the impact of this decision, we repeated the relevant analysis as any PrEP versus no PrEP during the relationship (see online Supplement). Partner PrEP and ART use were measured similarly, with our analyses also comparing use during all or none of the relationship.

We considered four steps of the seroadaptive cascade (Figure 1): knowledge of own status (Step 1), knowledge of partner's status (Step 2), serosorting (Step 3), and selection of sexual acts

(CLAI vs others; Step 4). We did not address seropositioning, as previous work found that this was much less common than other seroadaptive behaviors using either behavioral or intentionality definitions, and also had low consistency between those definitions [46]. 
medRxiv preprint doi: https://doi.org/10.1101/2020.11.25.20238758; this version posted November 29, 2020. The copyright holder for this preprint (which was not certified by peer review) is the author/funder, who has granted medRxiv a license to display the preprint in perpetuity.

It is made available under a CC-BY-NC-ND 4.0 International license .

At all cascade steps, we present our results in terms of the prevalence of each examined behavior by sub-group. This satisfies one of our goals: to provide a rich set of parameters for those modeling bio-behavioral prevention strategies among MSM in the presence of both PrEP and viral suppression. We then present tests of our hypotheses using exact binomial tests to calculate 95\% confidence intervals on estimates with a binary outcome, and Fisher's exact tests to compare estimates across groups.

\section{RESULTS}

Our inclusion criteria from the broader ARTnet study yielded 4,512 respondents, reporting on 13,800 relationships, or 3.1 relationships per respondent. These were slightly reduced relative to previous published analyses, since we excluded 392 respondents not asked about PrEP use early in the first wave. Table 1 lists descriptive statistics for the samples of both respondents and relationships. Overall, 9.5\% reported being diagnosed with HIV. One-time contacts represented just over half of reported relationships; main and casual relationships, with their longer durations, still reflected most of the relationship time and sexual acts. There were large numbers of relationships in which the respondent reported being HIV-negative and on $\operatorname{PrEP}(n=2,239)$ or HIV-negative and not on $\operatorname{PrEP}(n=7,937)$ throughout the relationship. However, the relationships reported by men diagnosed with HIV mostly comprised cases where they were on ART throughout $(n=1,126)$ with very few cases of no ART use $(n=69)$. We thus did not disaggregate any analyses of behaviors of HIV-positive respondents by own suppression status. 
Step 1. Figure 2 shows multiple measures for respondents' awareness of their own status. The proportion of respondents who reported ever having an HIV test rose rapidly from less than one in five in the mid-teens to near-universality around age 30, at which point it asymptoted with strong consistency across ages. Including all ages, the proportion with a test ever was $84.0 \%$, but including only respondents $25+$ raises this to $92.9 \%$, or for $30+$ to $94.4 \%$. Testing in the last two years followed the same pattern at young ages—-when nearly all testing would be recent—but diverged in the mid-20s, and experienced absolute decline beginning around age 30 . This trend was presumably driven in part by the increasing number of men who have tested positive by age, and thus do not require additional testing; this sub-group rose steadily with age until about 50, above which $19.9 \%$ of respondents reported having an HIV diagnosis. To determine the extent of this effect, we also plotted the proportion of men having a test in the last 2 years only among those who had never tested HIV-positive. This proportion suggests three rough phases in testing across the lifecourse for MSM who remain HIV-negative: one up through the mid-20s when testing is ramping up; one from then until near age 50 when testing is roughly stable, and one from age 50 when testing is in decline. Within the middle group, $82.7 \%$ had tested in the last two years. Collectively, these findings emphasize that, in subsequent analyses, respondents of "unknown" status largely reflect younger MSM, while those of positive status disproportionately reflect older men.

Step 2. Figure 3a depicts the proportion of partners for whom the respondent claims knowledge of their partner's serostatus, regardless of what that status was. Results are divided by respondent serostatus, PrEP status for negative respondents, and relational type. Overall, respondents reported knowing partner status in $68.3 \%$ of relationships. As hypothesized, the likelihood of 
It is made available under a CC-BY-NC-ND 4.0 International license .

knowing a partner's status declined with less committed relationship types, regardless of respondents' serostatus or PrEP status (Fisher's exact test, $\mathrm{p}<1 \mathrm{e}-7$ in all cases). We further hypothesized that negative men on PrEP would report lower status communication than negative men not on PrEP for a given relational type, especially for non-main relationships; however, we did not find evidence for a significance difference between these two populations (one-tailed Fisher's exact test, $\mathrm{p}>0.75$ for each relational type). Men on PrEP were more likely to know partner status than HIV-positive men were for casual and one-time partners, but not for main partners. Men who did not know their own HIV status reported the least knowledge of partner status overall; however, we note that even these men reported knowing their one-time partners' status fully half of the time. Redoing this comparison between relationships during which the respondent was never on PrEP versus ever (as opposed to always) on PrEP yielded qualitatively similar findings (Figure S1).

Step 3. The largest distinction in partner serostatus (conditional on the respondent reporting it as known) lay in the considerably higher proportion of HIV-positive partners for HIV-positive respondents over any other type of respondent, for all three partner types (Figure 3b), consistent with serosorting. As predicted, HIV-negative men on PrEP reported a higher proportion of known HIV-positive partners than did negative men not on $\operatorname{PrEP}(\mathrm{RR}=2.7$ overall). This association between respondent PrEP status and partner HIV status was particularly strong for main partners, with a RR of 4.2, compared to 2.9 for casual and 2.3 for one-time; however, all three were significant relative to the null of no difference by PrEP status (Fisher one-tailed exact tests, $\mathrm{p}<1 \mathrm{e}-5$ for all relationship types). Men on PrEP were the only population to show a significant difference in their proportion of HIV-positive partners across partner type (Fisher's 
medRxiv preprint doi: https://doi.org/10.1101/2020.11.25.20238758; this version posted November 29, 2020. The copyright holder for this preprint (which was not certified by peer review) is the author/funder, who has granted medRxiv a license to display the preprint in perpetuity.

It is made available under a CC-BY-NC-ND 4.0 International license .

exact test, $\mathrm{p}=3 \mathrm{e}-4)$. Those who reported not knowing their HIV status had responses most similar to HIV-negative men not on PrEP. Again, reanalysis to include PrEP use at any point in the relationship did not change the qualitative results (Figure S1).

Step 4. For act type and condom use behaviors, we focused on disaggregating by partner status rather than partner type, as the former is fundamental to the transmission potential associated with each behavior (Figure 4). HIV-negative respondents on PrEP had higher proportions of relationships with any CLAI than did HIV-negative respondents not on PrEP, for all partner serostatuses (one-tailed Fisher's exact test, $\mathrm{p}<1 \mathrm{e}-6$ in all cases). Indeed, the numbers for respondents on PrEP were similar to those of HIV-positive men ( $p>0.30$ in all cases). Again, responses for unknown-status respondents were most similar to those for HIV-negative men not on PrEP.

We note a consistent trend that we did not predict; for all types of respondents, regardless of status or PrEP use, CLAI was most likely to occur with known HIV-positive partners. Of course, the implications for this differ for HIV-positive versus HIV-negative men on or off PrEP. More than half of the relationships between HIV-negative respondents not on PrEP and their HIV-positive partners involved some CLAI, and the same was true for serostatus-unknown respondents. Since these types of relationships may entail the greatest transmission opportunity, we further disaggregated them by the respondent's report of their HIV-positive partner's use of ART. We did not see a significant difference among HIV-negative respondents not on PrEP in the probability of CLAI with HIV-positive partners on ART $(56.5 \%, 95 \% \mathrm{CI}=47.0 \%-65.7 \%$, $\mathrm{n}=115)$ versus off ART $(53.1 \%, 95 \% \mathrm{CI}=38.3 \%-67.5 \%, \mathrm{n}=49)$. We considered the same 
medRxiv preprint doi: https://doi.org/10.1101/2020.11.25.20238758; this version posted November 29, 2020. The copyright holder for this preprint (which was not certified by peer review) is the author/funder, who has granted medRxiv a license to display the preprint in perpetuity.

It is made available under a CC-BY-NC-ND 4.0 International license .

metrics for respondents on PrEP and also saw no significant difference (partners on ART: 80.0\%, 95\% CI $=71.3 \%-87.0 \%, \mathrm{n}=110$; partners off ART, 90.0\%, 95\% CI $=68.3 \%-98.8 \%, \mathrm{n}=20)$. One potential reason for the relatively high likelihood of CLAI with HIV-positive partners by all respondent types might be that they are more likely to be main partners than those of HIVnegative or HIV-unknown status, as seen in Figure 3. Table S1 (online supplement) reveals that, for each type of respondent (HIV-negative on and off PrEP, HIV-positive), CLAI is more likely with an HIV-positive main partner than HIV-positive one-time partner; however, the values for HIV-positive casual partners are similar those for main partners for each group of respondents.

\section{DISCUSSION}

In this study, we investigated four steps of the seroadaptive cascade in the era of biomedical prevention, comparing behaviors variously by serostatus knowledge, biomedical prevention use, and partnership type. We found that PrEP use does not have a discernible impact on status discussion, but does impact partner selection and the likelihood of having condomless anal intercourse. All groups of respondents were most likely to have CLAI with partners diagnosed with HIV, especially with main or casual partners. For respondents not diagnosed with HIV and not on PrEP, CLAI occurred in just over half of relationships with partners who were not on treatment. The probability that these respondents would have CLAI with one of their partners of unknown status was lower, but such partners were also much more common $(n=2283$, or $17.5 \%$ of all relationships). This suggests the persistence of sexual activity within known serodiscordant relationships in which men are aware of the absence of any form of prevention of HIV transmission, either biomedical or behavioral, as well as within many relationships where this 
medRxiv preprint doi: https://doi.org/10.1101/2020.11.25.20238758; this version posted November 29, 2020. The copyright holder for this

It is made available under a CC-BY-NC-ND 4.0 International license .

absence is a reasonable possibility. Both types represent key areas where identification and intervention continue to be needed, and could have substantial impact.

Our primary finding is broadly consistent with two recent studies that also disaggregated disclosure and partner status by respondent PrEP use. In an analysis that combined national and New York City samples, Grov et al. [34] found that HIV-negative men on PrEP had a higher proportion of positive casual partners than those off PrEP did (roughly 17\% and 11\% of their partners of known status, estimated from numbers in their Table 3.) Wang et al. [35] found similar numbers (17.1\% vs $9.3 \%$ of all partners with known status, respectively) in a Montrealbased sample. While the pattern of less serosorting by men on PrEP was consistent across all studies, our numbers suggest overall higher serosorting by HIV-negative men than these previous studies did $(8.7 \%$ and $3.1 \%$ known positive partners for men on or off PrEP in this study when averaged across partnership types, or $7.9 \%$ and $2.9 \%$ when excluding main partnerships for comparability to Grov et al.) Our sample is younger and more White than the US/NYC study, and more geographically diverse and less urban than the Montreal study, all of which may make HIV prevalence in the partner pool of our respondents lower overall. Because the previous studies did not disaggregate by relationship type, we cannot compare our findings to them in this regard. Our observation that men on PrEP have high rates of main partners known to be diagnosed with HIV (15.8\%) relative to other partner types undoubtedly reflects at least some reverse causality-i.e. an HIV-negative man with a main partner living with HIV is indicated for PrEP if they have anal sex, and would have high motivation to take it. For one-time partners, the number is smaller $(6.1 \%)$ and more similar to but still significantly above that of HIV-negative men off PrEP (2.6\%). All of these numbers are far below the comparable numbers for 
medRxiv preprint doi: https://doi.org/10.1101/2020.11.25.20238758; this version posted November 29, 2020. The copyright holder for this

It is made available under a CC-BY-NC-ND 4.0 International license .

respondents diagnosed with HIV, or indeed the proportion of MSM diagnosed with HIV in the US population [52]. Whether they reflect explicit serosorting by men on PrEP or partner selection on other attributes that correlate with status, the pattern does present evidence for a sexual network that remains fairly segregated between men who are or are not diagnosed with HIV, even as biomedical prevention has been touted as an option to allow individual MSM to more comfortably "bridge the serodivide" [53].

In contrast to our findings, these same two studies found that men with recent PrEP use were significantly more likely to know their partner's status than HIV-negative men without recent PrEP use (83\% versus 74\% for Grov et al.; 69.4\% versus 50.5\% for Wang et al.) Our comparable numbers, averaging across partner types included by each study, were $71.1 \%$ and $66.0 \%$ (for Grov et al.) and 74.0\% and 70.4\% (for Wang et al.) These trended in the same direction but were closer and not significantly different from each other. Regardless, all three studies agree that men on PrEP are not generally considering the protection it affords as a reason to engage in less serodiscussion. While we confirmed the expected trend by relational type, we also found that men on PreP were more likely than not (60.3)\% to report knowing even their one-time partners' HIV status. While one might imagine that knowledge of a main partner's serostatus would reflect overall intimacy and not solely concern for HIV transmission risk, this should be less true for casual and most especially one-time partners. The high rates of reported status knowledge by men on PrEP here may reflect multiple phenomena: (1) a continued desire by men on PrEP to assess their HIV risk, perhaps because of concern about their own adherence or other PrEP failures; (2) disclosure in the form of dating app profiles, which would occur automatically and without need for explicit discussion [54]; and (3) the mutuality of HIV status disclosure, such 
that men on PrEP are sharing and receiving HIV and biomedical status information for their partner's benefit [55]. The first of these includes cases where men on PrEP are not only seeking partners who are HIV-negative, but who themselves are on PrEP, to provide yet another layer of protection ("PrEP-sorting"); while we did not investigate this pattern here, both Grov et al. and Wang et al. found evidence for this phenomenon. Evidence for the second and third possibilities may come from our observation that men who report not knowing their own status still reported knowing their one-time partners' status more than half the time. It also highlights the possibility that some men report their status as negative to potential partners as long as they have never had an HIV-positive test result-even if they have never tested or tested very long ago [56].

We found that the first precursor for seroadaptation—having an HIV test—remains common, as one might expect given that accessing new biomedical prevention modalities still requires HIV screening, and the continued emphasis on testing by public health campaigns targeted at MSM. For MSM aged 25-49 who have not been diagnosed with HIV, roughly 5 out of 6 have tested in the last 2 years. However, those below age 25 show considerable room for improvements in testing, with only $58.4 \%$ aged $15-24$ testing in the last 2 years, or $63.8 \%$ of those $18-24$. This latter number is well below the 78.8\% of MSM aged 18-24 who had tested in the last 12 months in the most recent NHBS results [52], despite the latter testing time window being shorter. This may reflect differences in web-based versus venue sampling, and requires further investigation.

We found that men on PrEP were just as likely to have CLAI with their partners diagnosed with HIV $(83.2 \%)$ as were respondents who themselves were diagnosed with HIV (83.6\%). Since men on PrEP appeared to exhibit some level of seroadaptivity in terms of partner selection, we might 
then also anticipate that they would do so in terms of act selection and condom use; the high probability here and its similarity to the rate for respondents diagnosed with HIV suggests this does not appear to be the case.

Respondents of all serostatus and biomedical prevention status reported that CLAI was most likely with their partners who had diagnosed HIV. This finding for HIV-negative respondents implies that something other than simple seroadaptive behaviors is occurring. One likely explanation is selectivity—where those with the strongest propensity for CLAI acquire HIV at disproportionate rates and continue that propensity with their partners, including HIV-negative ones. Nevertheless, it is notable that this apparent effect is strong enough to reverse any tendency for selective use of condoms by HIV-negative men not on PrEP with their partners diagnosed with HIV.

Limitations. Our study relies on a convenience sample, as do all national surveys of MSM to some extent. Non-Hispanic White men were slightly over-represented, relative to the adult US male population, as were younger men. Nevertheless, a previous analysis of this data set found that, after accounting for unknown responses, HIV prevalence in the sample was in line with national estimates [47], and our median age matched that in the previous similar studies to which we compared our results $[34,35]$. It remains challenging to know how different respondents may interpret questions such as knowledge of partners' status-e.g., where some may assume a onetime partner's HIV-negative disclosure as truth while others report it as unknown. Again, however, it is presumably respondents' own perception of partner's status that most directly influences potential seroadaptive behavior. Answers to our questions were not necessarily the 
medRxiv preprint doi: https://doi.org/10.1101/2020.11.25.20238758; this version posted November 29, 2020. The copyright holder for this preprint (which was not certified by peer review) is the author/funder, who has granted medRxiv a license to display the preprint in perpetuity.

It is made available under a CC-BY-NC-ND 4.0 International license .

same way respondents would describe their status to a partner, especially for those whose last negative test was long ago. As with most serosorting studies, we do not have information on partnerships that did not occur specifically because of serodiscordance. Our inclusion of multiple hypothesis tests increases the overall Type 1 error rate and may yield false positives; we note, however, that all significant differences had $p$-values orders of magnitude below our significance level, and would thus hold up under a multiple comparison correction.

Conclusions. This study provides substantial new information on the recent magnitude of testing, disclosure, serosorting, sexual act selection, and use of condoms among US MSM. Our future work will incorporate this information into mechanistic transmission models, along with measures of imperfect adherence to PrEP and ART, to obtain estimates of the attributable fraction of transmissions among MSM occurring in different contexts, i.e. by relationship type and by the biomedical prevention methods used by the men in these relationships. Such work would be relevant for HIV as well as for other major reportable STIs (e.g., syphilis), which circulate on the same sexual network as HIV. With more than 25,000 new HIV diagnoses among US MSM each year still, such models are critical to identify the conditions where prevention efforts-biomedical and behavioral—remain insufficient, as we work towards the goal of ending the HIV epidemic. 
medRxiv preprint doi: https://doi.org/10.1101/2020.11.25.20238758; this version posted November 29, 2020. The copyright holder for this preprint (which was not certified by peer review) is the author/funder, who has granted medRxiv a license to display the preprint in perpetuity.

It is made available under a CC-BY-NC-ND 4.0 International license .

\section{FUNDING}

This work was supported by National Institutes of Health grants R21 MH112449 and R01

AI138783. Partial support for this research came from a Eunice Kennedy Shriver National

Institute of Child Health and Human Development research infrastructure grant, P2C HD042828, to the Center for Studies in Demography and Ecology at the University of Washington.

\section{ACKNOWLEDGMENTS}

The authors would like to thank the study participants, the full AMIS and ARTnet research teams, and the Network Modeling Group at the University of Washington.

\section{COMPLIANCE WITH ETHICAL STANDARDS}

\section{Disclosure of potential conflicts of interest}

The authors have no conflicts of interest to declare that are relevant to the content of this article.

\section{Research involving Human Participants}

This study was approved by the Emory University Institutional Review Board. It was performed in accordance with the ethical standards laid down in the 1964 Declaration of Helsinki and its later amendments.

\section{Informed consent}

Informed consent was obtained from all individual participants included in the study. 
medRxiv preprint doi: https://doi.org/10.1101/2020.11.25.20238758; this version posted November 29, 2020. The copyright holder for this preprint (which was not certified by peer review) is the author/funder, who has granted medRxiv a license to display the preprint in perpetuity.

It is made available under a CC-BY-NC-ND 4.0 International license .

TABLE 1: Descriptive statistics for respondents and relationships

\begin{tabular}{lrr} 
& $\begin{array}{r}\text { Individual-level } \\
(\mathrm{n}=4,512)\end{array}$ & $\begin{array}{r}\text { Relationship-level } \\
(\mathrm{n}=13,800)\end{array}$ \\
\hline Respondent median age [IQR] & $34[24-49]$ & $33[24-49]$ \\
\hline Race/ethnicity of respondent & & \\
$\quad$ Black (non-Hispanic) & $232 / 4512(5.1 \%)$ & $615 / 13800(4.5 \%)$ \\
$\quad$ Hispanic & $626 / 4512(13.9 \%)$ & $2005 / 13800(14.5 \%)$ \\
White (non-Hispanic) & $3250 / 4512(72.0 \%)$ & $9988 / 13800(72.4 \%)$ \\
Others & $404 / 4512(9.0 \%)$ & $1192 / 13800(8.6 \%)$ \\
\hline Self-reported HIV status of respondent & & \\
HIV-negative & $3334 / 4512(73.9 \%)$ & $10680 / 13800(77.4 \%)$ \\
HIV-positive & $428 / 4512(9.5 \%)$ & $1300 / 13800(9.4 \%)$ \\
Don't know & $750 / 4512(16.6 \%)$ & $1820 / 13800(13.2 \%)$ \\
\hline Relationship type & & $2076 / 13800(15.0 \%)$ \\
Main & & $4751 / 13800(34.4 \%)$ \\
Casual & & $6973 / 13800(50.5 \%)$ \\
$\quad$ One-time & &
\end{tabular}

Ever taken PrEP (HIV-neg. respondents)

Yes

No

On PrEP during this relationship (HIV-

neg. respondents)

Entire time

$2239 / 10680(21.0 \%)$

Some of the time

$448 / 10680(4.2 \%)$

None of the time

$7937 / 10680(74.3 \%)$

Not sure/no answer

$56 / 10680(0.5 \%)$

On antiretroviral medication during this

relationship (HIV-pos. respondents)

Entire time

$1126 / 1300(86.6 \%)$

Some of the time

48/1300 ( $3.7 \%)$

None of the time

$69 / 1300(5.3 \%)$

Not sure/no answer

$57 / 1300(4.4 \%)$

$\mathrm{IQR}=$ interquartile range 
medRxiv preprint doi: https://doi.org/10.1101/2020.11.25.20238758; this version posted November 29, 2020. The copyright holder for this preprint (which was not certified by peer review) is the author/funder, who has granted medRxiv a license to display the preprint in perpetuity.

It is made available under a CC-BY-NC-ND 4.0 International license .

\section{FIGURE 1}

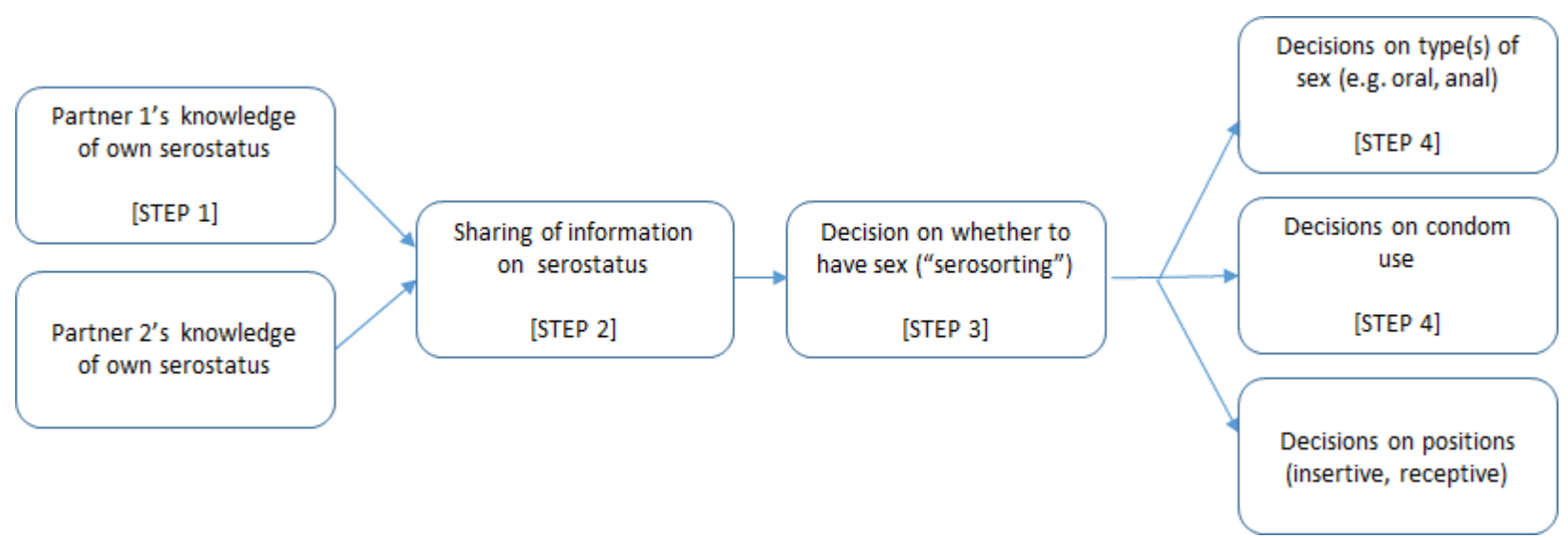


medRxiv preprint doi: https://doi.org/10.1101/2020.11.25.20238758; this version posted November 29, 2020. The copyright holder for this preprint (which was not certified by peer review) is the author/funder, who has granted medRxiv a license to display the preprint in perpetuity.

It is made available under a CC-BY-NC-ND 4.0 International license .

\section{FIGURE 2}

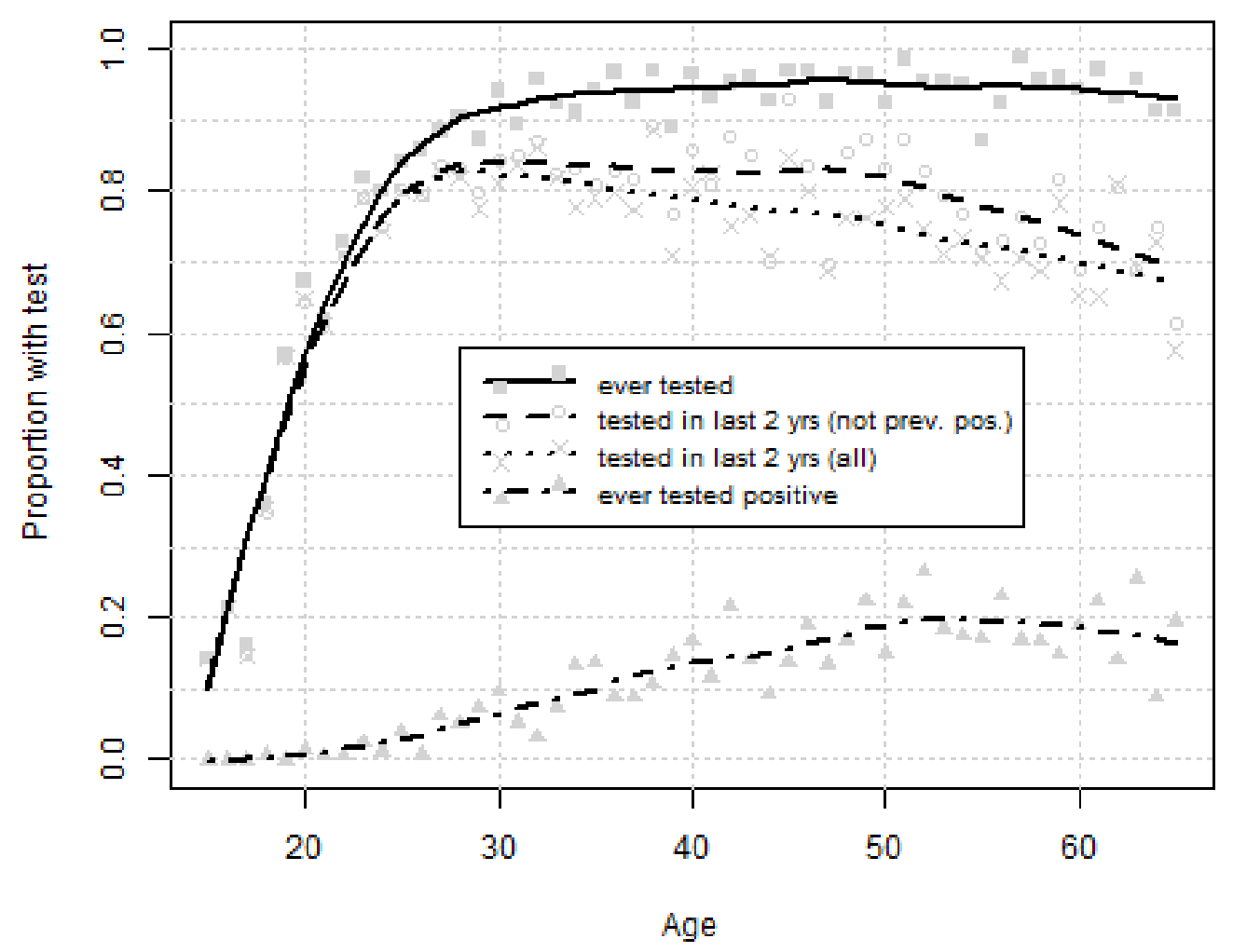


medRxiv preprint doi: https://doi.org/10.1101/2020.11.25.20238758; this version posted November 29, 2020. The copyright holder for this preprint (which was not certified by peer review) is the author/funder, who has granted medRxiv a license to display the preprint in perpetuity.

It is made available under a CC-BY-NC-ND 4.0 International license .

\section{FIGURE 3}

\section{A. Partners with known status}

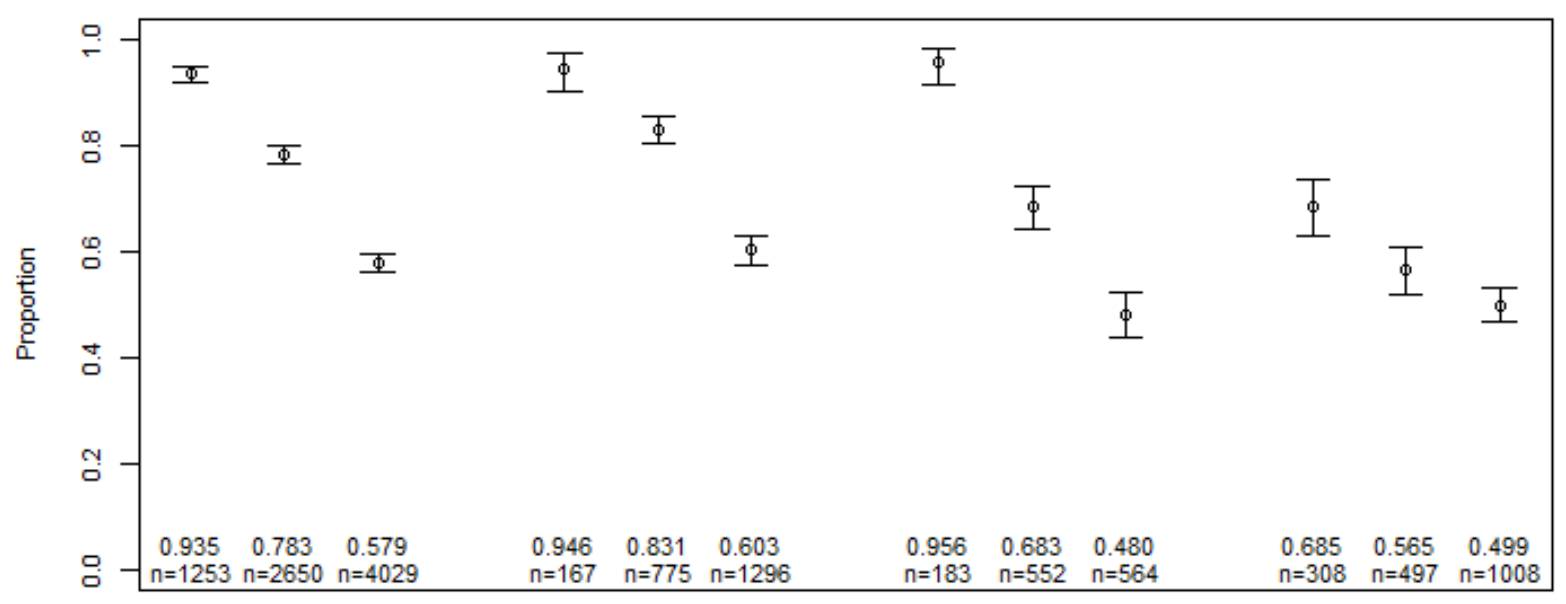

\section{B. Partners with known HIV-positive status}

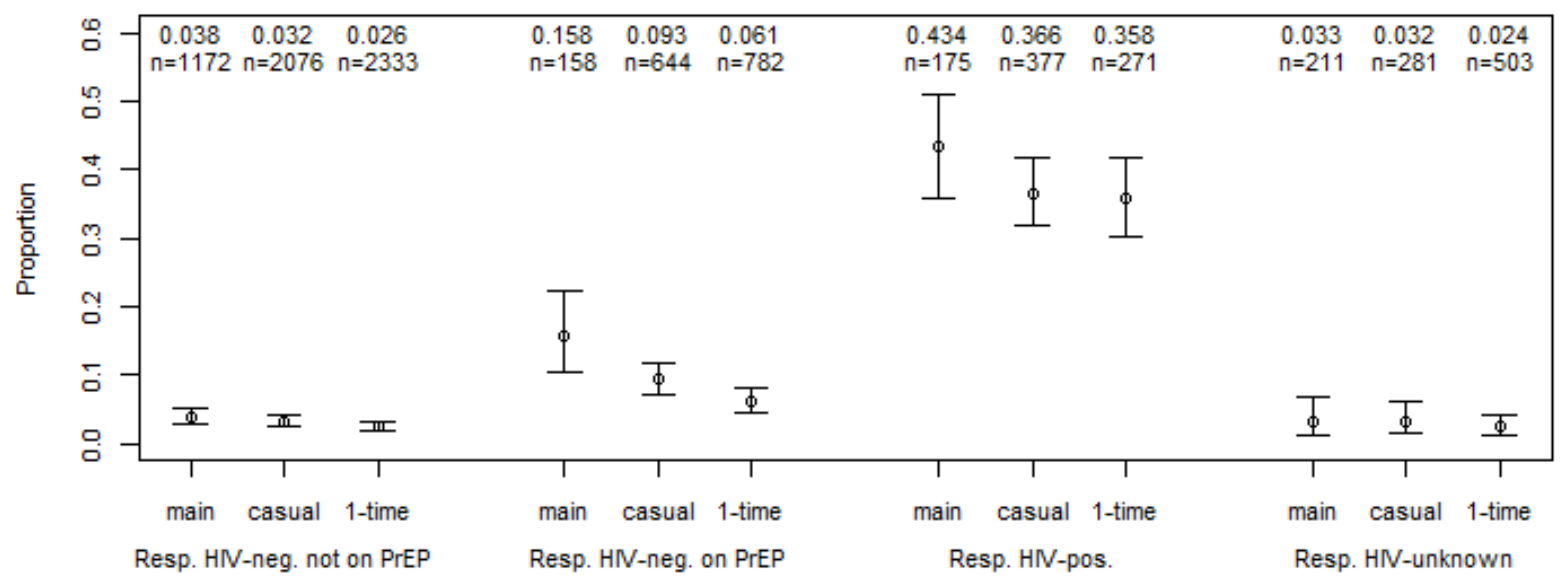


medRxiv preprint doi: https://doi.org/10.1101/2020.11.25.20238758; this version posted November 29, 2020. The copyright holder for this preprint (which was not certified by peer review) is the author/funder, who has granted medRxiv a license to display the preprint in perpetuity.

It is made available under a CC-BY-NC-ND 4.0 International license .

\section{FIGURE 4}
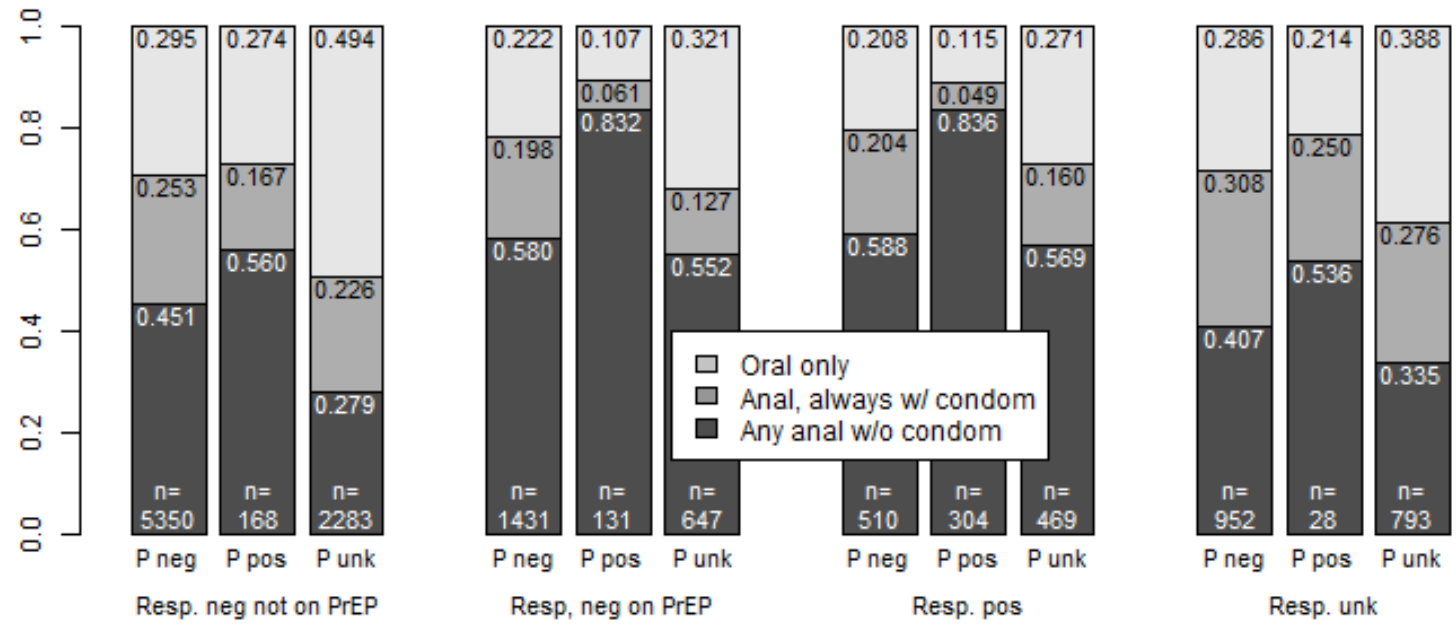

Serostatus combination (respondent, partner) 


\section{FIGURE CAPTIONS}

FIGURE 1: A seroadaptive cascade framework. This provides a schematic of the major elements of seroadaptive behaviors, including the precursor of testing. Steps refer to the components of the analysis in the paper, and do not imply that all of these must occur or, if they do occur, will do so in this exact order. For example, men do not need to know their serostatus to share information (i.e. one can share the fact that one has never tested for HIV), and the decision to have sex can occur without any serostatus discussion at all. In practice, components may also be iterative rather than discretely ordered; for example, a man may change his mind and decide not to have sex if he and a prospective partner cannot agree about sexual type or condom use.

FIGURE 2: Measures of respondents' knowledge of their own HIV status, by age. From top to bottom, metrics reflect the proportion at each age who report ever having had an HIV test; the proportion who have had an HIV test in the last 2 years, out of those who have not previously been diagnosed positive; the proportion overall who have had an HIV test in the last 2 years; and the proportion who have ever tested positive for HIV. Dots reflect the mean value for respondents of a given age. Lines represent loess curves with $\alpha=0.5$, as implemented with the loess command in R v. 4.0.2.

FIGURE 3: Partner status, by respondent HIV status and relationship type: (a) Proportion of partners whose HIV status respondents report knowing; (b) Proportion of partners who respondents report as HIV-positive, among partners of known status. CIs = binomial proportion confidence intervals, selected due to the binary outcome and the small sample sizes in some 
medRxiv preprint doi: https://doi.org/10.1101/2020.11.25.20238758; this version posted November 29, 2020. The copyright holder for this preprint (which was not certified by peer review) is the author/funder, who has granted medRxiv a license to display the preprint in perpetuity. It is made available under a CC-BY-NC-ND 4.0 International license .

categories. Relationship types are defined in the text. Note the difference in scale on the $y$-axis to make visible the differences by relational type in Figure 3B.

FIGURE 4: Sexual acts and condom use within relationships, by respondent HIV status and PrEP use and partner HIV status. Relationships are categorized by act with highest transmission probability, i.e. a relationship listed as "anal, always w/ condom” may also contain oral sex acts, while "any anal without condom" may also contain anal sex with condom and/or oral sex. P neg = partner HIV-negative; $\mathrm{P}$ pos = partner HIV-positive; $\mathrm{P}$ unk = partner HIV status unknown 


\section{LITERATURE CITED}

1. Cairns G. New directions in HIV prevention: serosorting and universal testing. IAPAC monthly. Feb 2006;12(2):42-45.

2. Cassels S, Menza TW, Goodreau SM, Golden MR. HIV serosorting as a harm reduction strategy: evidence from Seattle, Washington. Aids. Nov 27 2009;23(18):2497-2506.

3. Cassels S, Katz DA. Seroadaptation among men who have sex with men: emerging research themes. Current HIV/AIDS reports. Dec 2013;10(4):305-313.

4. Chen YH, Snowden JM, McFarland W, Raymond HF. Pre-exposure Prophylaxis (PrEP) Use, Seroadaptation, and Sexual Behavior Among Men Who Have Sex with Men, San Francisco, 2004-2014. AIDS and behavior. Dec 2016;20(12):2791-2797.

5. Grov C, Rendina HJ, Moody RL, Ventuneac A, Parsons JT. HIV Serosorting, Status Disclosure, and Strategic Positioning Among Highly Sexually Active Gay and Bisexual Men. AIDS patient care and STDs. Oct 2015;29(10):559-568.

6. Halkitis PN, Moeller RW, Pollock JA. Sexual practices of gay, bisexual, and other nonidentified MSM attending New York City gyms: patterns of serosorting, strategic positioning, and context selection. Journal of sex research. Jul-Sep 2008;45(3):253-261.

7. Jin F, Prestage GP, Templeton DJ, et al. The impact of HIV seroadaptive behaviors on sexually transmissible infections in HIV-negative homosexual men in Sydney, Australia. Sexually transmitted diseases. Mar 2012;39(3):191-194.

8. Khosropour CM, Dombrowski JC, Swanson F, et al. Trends in Serosorting and the Association With HIV/STI Risk Over Time Among Men Who Have Sex With Men. Journal of acquired immune deficiency syndromes. Jun 1 2016;72(2):189-197.

9. Kurtz SP, Buttram ME, Surratt HL, Stall RD. Resilience, syndemic factors, and serosorting behaviors among HIV-positive and HIV-negative substance-using MSM. AIDS education and prevention : official publication of the International Society for AIDS Education. Jun 2012;24(3):193-205.

10. LeVasseur MT, Goldstein ND, Tabb LP, Olivieri-Mui BL, Welles SL. The Effect of PrEP on HIV Incidence Among Men Who Have Sex With Men in the Context of 
Condom Use, Treatment as Prevention, and Seroadaptive Practices. Journal of acquired immune deficiency syndromes. Jan 1 2018;77(1):31-40.

11. Marks G, Millett GA, Bingham T, Lauby J, Murrill CS, Stueve A. Prevalence and protective value of serosorting and strategic positioning among Black and Latino men who have sex with men. Sexually transmitted diseases. May 2010;37(5):325-327.

12. McFarland W, Chen YH, Raymond HF, et al. HIV seroadaptation among individuals, within sexual dyads, and by sexual episodes, men who have sex with men, San Francisco, 2008. AIDS care. Mar 2011;23(3):261-268.

13. Murphy RD, Gorbach PM, Weiss RE, Hucks-Ortiz C, Shoptaw SJ. Seroadaptation in a sample of very poor Los Angeles area men who have sex with men. AIDS and behavior. Jun 2013;17(5):1862-1872.

14. Parsons JT, Schrimshaw EW, Wolitski RJ, et al. Sexual harm reduction practices of HIVseropositive gay and bisexual men: serosorting, strategic positioning, and withdrawal before ejaculation. Aids. Apr 2005;19 Suppl 1:S13-25.

15. Paz-Bailey G, Mendoza MC, Finlayson T, et al. Trends in condom use among MSM in the United States: the role of antiretroviral therapy and seroadaptive strategies. Aids. Jul 31 2016;30(12):1985-1990.

16. Philip SS, Yu X, Donnell D, Vittinghoff E, Buchbinder S. Serosorting is associated with a decreased risk of HIV seroconversion in the EXPLORE Study Cohort. PloS one. Sep 9 2010;5(9).

17. Reniers G, Helleringer S. Serosorting and the evaluation of HIV testing and counseling for HIV prevention in generalized epidemics. AIDS and behavior. Jan 2011;15(1):1-8.

18. Ronn M, White PJ, Hughes G, Ward H. Developing a conceptual framework of seroadaptive behaviors in HIV-diagnosed men who have sex with men. The Journal of infectious diseases. Dec 1 2014;210 Suppl 2:S586-593.

19. Siegler AJ, Sullivan PS, Khosropour CM, Rosenberg ES. The role of intent in serosorting behaviors among men who have sex with men sexual partnerships. Journal of acquired immune deficiency syndromes. Nov 1 2013;64(3):307-314.

20. Snowden JM, Raymond HF, McFarland W. Prevalence of seroadaptive behaviours of men who have sex with men, San Francisco, 2004. Sexually transmitted infections. Oct 2009;85(6):469-476. 
medRxiv preprint doi: https://doi.org/10.1101/2020.11.25.20238758; this version posted November 29, 2020. The copyright holder for this preprint (which was not certified by peer review) is the author/funder, who has granted medRxiv a license to display the preprint in perpetuity.

It is made available under a CC-BY-NC-ND 4.0 International license .

21. Vallabhaneni S, Li X, Vittinghoff E, Donnell D, Pilcher CD, Buchbinder SP.

Seroadaptive practices: association with HIV acquisition among HIV-negative men who have sex with men. PloS one. 2012;7(10):e45718.

22. Vallabhaneni S, McConnell JJ, Loeb L, et al. Changes in seroadaptive practices from before to after diagnosis of recent HIV infection among men who have sex with men. PloS one. 2013;8(2):e55397.

23. van den Boom W, Stolte I, Sandfort T, Davidovich U. Serosorting and sexual risk behaviour according to different casual partnership types among MSM: the study of onenight stands and sex buddies. AIDS care. 2012;24(2):167-173.

24. Wei C, Raymond HF, Guadamuz TE, et al. Racial/Ethnic differences in seroadaptive and serodisclosure behaviors among men who have sex with men. AIDS and behavior. Jan 2011;15(1):22-29.

25. Wilton L, Koblin B, Nandi V, et al. Correlates of Seroadaptation Strategies Among Black Men Who have Sex with Men (MSM) in 4 US Cities. AIDS and behavior. Dec 2015;19(12):2333-2346.

26. Eaton LA, Kalichman SC, Cain DN, et al. Serosorting sexual partners and risk for HIV among men who have sex with men. American journal of preventive medicine. Dec 2007;33(6):479-485.

27. Golden MR, Stekler J, Hughes JP, Wood RW. HIV serosorting in men who have sex with men: is it safe? Journal of acquired immune deficiency syndromes. Oct 1 2008;49(2):212218.

28. Zablotska IB, Imrie J, Prestage G, et al. Gay men's current practice of HIV seroconcordant unprotected anal intercourse: serosorting or seroguessing? AIDS care. Apr 2009;21(4):501-510.

29. McFarland W, Chen YH, Nguyen B, et al. Behavior, intention or chance? A longitudinal study of HIV seroadaptive behaviors, abstinence and condom use. AIDS and behavior. Jan 2012;16(1):121-131.

30. Sanchez TH, Zlotorzynska M, Sineath RC, Kahle E, Tregear S, Sullivan PS. National Trends in Sexual Behavior, Substance Use and HIV Testing Among United States Men Who have Sex with Men Recruited Online, 2013 Through 2017. AIDS and behavior. Aug 2018;22(8):2413-2425. 
31. Kennedy CE, Bernard LJ, Muessig KE, et al. Serosorting and HIV/STI Infection among HIV-Negative MSM and Transgender People: A Systematic Review and Meta-Analysis to Inform WHO Guidelines. Journal of sexually transmitted diseases. 2013;2013:583627.

32. Purcell DW, Higa D, Mizuno Y, Lyles C. Quantifying the Harms and Benefits from Serosorting Among HIV-Negative Gay and Bisexual Men: A Systematic Review and Meta-analysis. AIDS and behavior. Oct 2017;21(10):2835-2843.

33. Chen YH, Guigayoma J, McFarland W, Snowden JM, Raymond HF. Increases in Preexposure Prophylaxis Use and Decreases in Condom Use: Behavioral Patterns Among HIV-Negative San Francisco Men Who have Sex with Men, 2004-2017. AIDS and behavior. Jul 2019;23(7):1841-1845.

34. Grov C, Jonathan Rendina H, Patel VV, Kelvin E, Anastos K, Parsons JT. Prevalence of and Factors Associated with the Use of HIV Serosorting and Other Biomedical Prevention Strategies Among Men Who Have Sex with Men in a US Nationwide Survey. AIDS and behavior. Aug 2018;22(8):2743-2755.

35. Wang L, Moqueet N, Lambert G, et al. Population-Level Sexual Mixing According to HIV Status and Preexposure Prophylaxis Use Among Men Who Have Sex With Men in Montreal, Canada: Implications for HIV Prevention. American journal of epidemiology. Jan 31 2020;189(1):44-54.

36. Liu AY, Cohen SE, Vittinghoff E, et al. Preexposure Prophylaxis for HIV Infection Integrated With Municipal- and Community-Based Sexual Health Services. JAMA internal medicine. Jan 2016;176(1):75-84.

37. Kelley CF, Kahle E, Siegler A, et al. Applying a PrEP Continuum of Care for Men Who Have Sex With Men in Atlanta, Georgia. Clinical infectious diseases : an official publication of the Infectious Diseases Society of America. Nov 15 2015;61(10):15901597.

38. Maxwell S, Gafos M, Shahmanesh M. Pre-exposure Prophylaxis Use and Medication Adherence Among Men Who Have Sex With Men: A Systematic Review of the Literature. The Journal of the Association of Nurses in AIDS Care : JANAC. Jul-Aug 2019;30(4):e38-e61.

39. Mustanski B, Ryan DT, Remble TA, D'Aquila RT, Newcomb ME, Morgan E. Discordance of Self-report and Laboratory Measures of HIV Viral Load Among Young 
Men Who Have Sex with Men and Transgender Women in Chicago: Implications for Epidemiology, Care, and Prevention. AIDS and behavior. Jul 2018;22(7):2360-2367.

40. Stephenson R, Bratcher A, Mimiaga MJ, et al. Brief Report: Accuracy in Self-Report of Viral Suppression Among HIV-Positive Men With HIV-Negative Male Partners. Journal of acquired immune deficiency syndromes. Mar 1 2020;83(3):210-214.

41. To KW, Lee SS. A review of reported cases of HIV pre-exposure prophylaxis failure with resultant breakthrough HIV infections. HIV medicine. Nov 32020.

42. Hoff C. Negotiated safety agreements: do they protect and how they protect. Focus. Feb $2005 ; 20(2): 1-5$.

43. Hoff CC, Beougher SC. Sexual agreements among gay male couples. Archives of sexual behavior. Jun 2010;39(3):774-787.

44. Starks TJ, Payton G, Golub SA, Weinberger CL, Parsons JT. Contextualizing condom use: intimacy interference, stigma, and unprotected sex. Journal of health psychology. Jun 2014;19(6):711-720.

45. Golub SA, Starks TJ, Payton G, Parsons JT. The critical role of intimacy in the sexual risk behaviors of gay and bisexual men. AIDS and behavior. Apr 2012;16(3):626-632.

46. Khosropour CM, Dombrowski JC, Hughes JP, Manhart LE, Simoni JM, Golden MR. Operationalizing the Measurement of Seroadaptive Behaviors: A Comparison of Reported Sexual Behaviors and Purposely-Adopted Behaviors Among Men who have Sex with Men (MSM) in Seattle. AIDS and behavior. Oct 2017;21(10):2935-2944.

47. Weiss KM, Goodreau SM, Morris M, et al. Egocentric sexual networks of men who have sex with men in the United States: Results from the ARTnet study. Epidemics. Jan 24 2020;30:100386.

48. Sanchez TH, Sineath RC, Kahle EM, Tregear SJ, Sullivan PS. The Annual American Men's Internet Survey of Behaviors of Men Who Have Sex With Men in the United States: Protocol and Key Indicators Report 2013. JMIR public health and surveillance. Jan-Jun 2015;1(1):e3.

49. Zlotorzynska M, Cantu C, Rai R, Sullivan P, Sanchez T. The Annual American Men's Internet Survey of Behaviors of Men Who Have Sex With Men in the United States: 2017 Key Indicators Report. JMIR public health and surveillance. Apr 13 2020;6(2):e16847. 
medRxiv preprint doi: https://doi.org/10.1101/2020.11.25.20238758; this version posted November 29, 2020. The copyright holder for this preprint (which was not certified by peer review) is the author/funder, who has granted medRxiv a license to display the preprint in perpetuity.

It is made available under a CC-BY-NC-ND 4.0 International license .

50. Zlotorzynska M, Sullivan P, Sanchez T. The Annual American Men's Internet Survey of Behaviors of Men Who Have Sex With Men in the United States: 2015 Key Indicators Report. JMIR public health and surveillance. Mar 25 2017;3(1):e13.

51. Zlotorzynska M, Sullivan P, Sanchez T. The Annual American Men's Internet Survey of Behaviors of Men Who Have Sex With Men in the United States: 2016 Key Indicators Report. JMIR public health and surveillance. Feb 20 2019;5(1):e11313.

52. Centers for Disease Control and Prevention. HIV Infection Risk, Prevention, and Testing Behaviors Among Men Who Have Sex With Men-National HIV Behavioral Surveillance, 23 U.S. Cities, 2017. HIV Surveillance Special Report 22. https://www.cdc.gov/hiv/library/reports/hiv-surveillance.html. Published February 2019. Accessed Sep 21, 2020. gg.

53. Koester KA, Erguera XA, Kang Dufour MS, et al. "Losing the Phobia:" Understanding How HIV Pre-exposure Prophylaxis Facilitates Bridging the Serodivide Among Men Who Have Sex With Men. Frontiers in public health. 2018;6:250.

54. Medina MM, Crowley C, Montgomery MC, et al. Disclosure of HIV Serostatus and Preexposure Prophylaxis Use on Internet Hookup Sites Among Men Who have Sex with Men. AIDS and behavior. Jul 2019;23(7):1681-1688.

55. Holt M, Rawstorne P, Worth H, Bittman M, Wilkinson J, Kippax S. Predictors of HIV disclosure among untested, HIV-negative and HIV-positive Australian men who had anal intercourse with their most recent casual male sex partner. AIDS and behavior. Aug 2011;15(6):1128-1139.

56. Grov C, Rendina HJ, Parsons JT. How Different are Men Who Do Not Know Their HIV Status from Those Who Do? Results from an U.S. Online Study of Gay and Bisexual Men. AIDS and behavior. Sep 2016;20(9):1989-1999. 